were to a point which Young could never hope to reach, were posterior to, and probably determined by, Young's fundamental contribution.

"In a lapidary inscription a man is not upon oath," said Johnson. That is very true; and the great mass of such inscriptions may be permitted an affectionate exaggeration of the qualities of the departed. But when we read on the tablet in- scribed to Young's memory in Westminster Abbey a eulogium of Young as one who "alike eminent in almost every department of human learning, patient of unintermitted labour, endowed with the faculty of intuitive perception . . . first penetrated the obscurity which had veiled for ages the Hieroglyphics of Egypt", we are reading no more than the literal and unadorned truth.

\title{
Oil and Petrol from Coal*
}

By Prof. C. H. Lander, C.B.E.

$\mathrm{A}^{\mathrm{LT}}$ LL fuels consist essentially of carbon and hydro. gen combined in different proportions. In oil, the proportion of hydrogen to carbon is higher than in coal ; further, oil contains less oxygen than coal. It is thus obvious that in order to turn coal into oil the proportions of carbon, hydrogen, and oxygen must be suitably readjusted. Various ways of doing this have suggested themselves to the scientific mind, but oil was first produced commercially from coal almost, as it were, accidentally, for it is one of the by-products in the manufacture of gas from coal.

Gas is made by the destructive distillation of coal, usually termed carbonisation. In this process, the coal is heated to a high temperature in closed retorts; the gas and condensable vapours which are driven off are collected, and from the resulting liquid products a certain quantity of oil can be prepared. In the course of these reactions there is a redistribution of the carbon and hydrogen atoms ; the coke, which is left behind in the retort, consists mainly of carbon, and has a lower proportion of hydrogen than the original coal, while the liquid and gaseous products have a higher proportion of hydrogen than the original coal.

If the carbonisation is carried out at a lower temperature, say at a dull red heat instead of the bright white heat associated with normal gasmaking processes, the yield of gas is less and the yields of coke and liquid products greater, while the latter are more nearly akin to natural petroleum. This process is usually known as low-temperature carbonisation.

Since light spirit is at the present time far more valuable than heavy oils, there have been introduced methods of again redistributing the molecules in the liquid products from the carbonisation of coal, so as to obtain higher yields of the lighter spirit. During this process, which is known as cracking, a residue, which has been deprived of hydrogen, appears as coke. Cracking is also widely applied to the heavier fractions obtained in the distillation of petrol from natural oils.

In obtaining petrol directly from the carbonisation of coal, low temperature carbonisation, cracking pushed to its limits, and the scrubbing of the gas to recover further small quantities of light spirit have not up to the present been able to raise

* From the Friday evening discourse at the Royal Institution delivered on Nov. 20, 1931.

No. 3261, VoL. 129] the total yield of motor spirit beyond 6-7 gallons per ton of raw coal. It must, however, not be forgotten that the primary object of carbonisation processes is the manufacture of coke and gas, and that light spirit, valuable as it may be per gallon, is still only a by-product.

The enormous importance of oil and petrol in modern civilisation has naturally focused attention on the possibilities of reshuffling the molecules in the coal in a way favourable to greater oil production; but, as I have already pointed out, coal, as compared with oil, is deficient in hydrogen. The possibility therefore suggests itself of adding extra

\begin{tabular}{|c|c|c|c|} 
CARBON & \multicolumn{3}{|c|}{$\mathrm{H}_{2} \mathrm{O}_{2} \mathrm{NH}_{3}$} \\
\hline 95 & 5 & 12 \\
\hline 93 & 7 & 5 & HEAVY OIL \\
\hline 91 & 9 & 3 & MIDDLE OIL \\
\hline 88 & 12 & PETROL \\
\hline
\end{tabular}

FIG. 1.

hydrogen to the coal substance in order to make up this deficiency, and then, by some means or other, inducing the molecules of the mixture to reshuffle themselves into oil molecules. This has actually been accomplished, and for this success due credit must be paid to the work of Dr. Friedrich Bergius, at Mannheim, who was the first to liquefy coal by direct hydrogenation.

Important and striking developments of the hydrogenation process as applied to coal have been made during the past six years, in Great Britain mainly by the Fuel Research Board and Imperial Chemical Industries, Ltd. Fig. $1 \dagger$ shows how the oxygen, nitrogen, and sulphur in the coal are removed as water, ammonia, and sulphuretted hydrogen. The residual hydrocarbons in the coal (95 per cent $\mathrm{C}, 5$ per cent $\mathrm{H}$ ) break down and combine with hydrogen to give a large percentage of petrol (88 per cent $\mathrm{C}, 12$ per cent $\mathrm{H}$ ), the solid material probably passing through heavy oil (93 per cent $\mathrm{C}$, 7 per cent $H$ ) and middle oil (91 per cent $C, 9$ per cent $\mathrm{H}$ ). It will be seen that although at present

+ For this and the other illustrations selected from the original discourse for publication here, thanks are due to Imperial Chemical Industries, Ltd. 
petrol forms the most attractive product on account of its comparatively high price, the process could be stopped at an intermediate stage and so made to yield kerosene, diesel oil, or fuel oil.

So important to the interests of Great Britain did the possibilities of the hydrogenation of coal appear that active work was inaugurated at the Fuel Research Station in 1922, with results so encouraging that in 1926 an intermediate-scale continuous plant, on the lines of Bergius' latest development, was set up at the Fuel Research Station, and, largely through the foresight of Dr. W. R. Ormandy, who had organised a syndicate to explore the possibility of applying the Bergius process to British coal, an agreement was entered into between the British Government and Dr. Bergius for the pooling and mutual discussion of the results obtained in both laboratories.

\section{Bergius Process}

The Bergius process consists essentially in subjecting coal to the action of hydrogen at a high temperature and a high pressure. The powdered coal is prepared for treatment by mixing it with a small quantity of alkaline iron oxide (luxmasse), which acts as a catalyst, and a suitable oil or tar, which may be a fraction of the liquid product obtained from previous runs.

For the preliminary exploration of the process on a small scale, converters consisting of steelwalled vessels, closed by means of a blank flange, and of capacity about 2 litres, are used. A spindle projects from each end of the closed converter so that it can be carried on bearings and rotated over a row of gas flames. The pressure is measured by means of a gauge attached to one of the spindles through which there is drilled a passage to the interior of the vessel, and the temperature is measured by a thermocouple contained within a closed tube carried by the cover and projecting into the converter along its axis.

In hydrogenating coal by the original Bergius process, a thoroughly well-mixed paste is made from 20 parts of coal, 1 part of iron oxide (luxmasse), and 8 parts of oil, the oil being taken from some of the heavier fractions obtained from previous runs. This paste is inserted into the converter, which is then closed. Hydrogen is pumped into the converter until a pressure of about $100 \mathrm{~atm}$. is reached, when the converter is placed in its bearings and rotated over the gas flames, the temperature being raised to about $450^{\circ} \mathrm{C}$., while the pressure at the same time rises to about 200 atm. The reaction is allowed to proceed for two hours, after which the converter is cooled and the products extracted.

In these discontinuous experiments it is possible to use coal either in the dry powdered state or in a paste. In a continuous plant, however, there would be great difficulty in injecting a solid material in powdered form into an enclosure which is already under a high gaseous (hydrogen) pressure. By mixing the fine coal with oil into a paste a material is obtained which can be pumped, and this expedient formed one of the most important claims in the Bergius patents.

In the small continuous Bergius plant, capable of dealing with about one ton a day, installed at the Fuel Research Station, the product is a relatively mobile oil, and the rough balance-sheet of the process shows that 50 per cent of the coal is transformed into distillable oil, 20 per cent into gas, and about 15 per cent remains as partially converted material. Some of the partially converted solids remain in suspension in a very fine state in the crude hydrogenated product, and make it very difficult to distil, but by taking proper precautions a series of fractions can be obtained. The heavier fractions can be rehydrogenated for the production of a further quantity of light spirit.

\section{Funl Research Station Modified Process}

Further experimental work was carried out at the Fuel Research Station in order to increase the yield of the lighter fractions at the expense of the heavier oils, and to examine the process in the absence of a complicating factor such as a liquid vehicle for converting the coal into a paste. Improved catalysts were used, and the work was carried out in two stages. In the first stage, coal mixed with a suitable catalyst was heated under pressure in a stream of hydrogen. The reaction products were carried over by the hydrogen and through a second catalyst, in which further conversion to motor spirit took place in the gaseous phase. Experiments have been carried out using $50 \mathrm{lb}$. of clean coal, and a yield of 140 gal. of motor spirit was obtained per ton of dry, ash-free coal. The net hydrogen required amounted to 8.8 per cent by weight of the coal, giving, together with the $5 \cdot 6$ per cent already present, a total of 14.4 per cent of hydrogen required for the reactions.

The yields of the different products obtained in the processes of high and low temperature carbonisation and a hydrogenation process are shown in the accompanying table:

Yields from Bituminous Coals submitted to Different Treatments

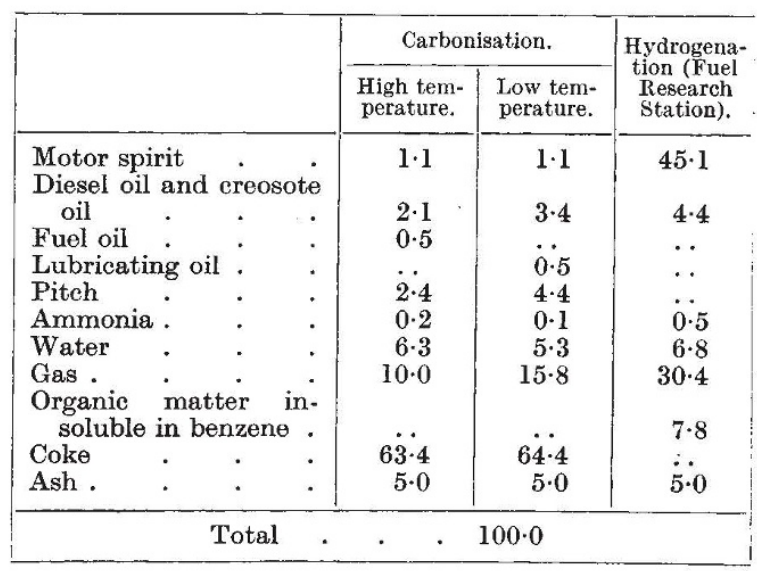

(To be continued.) 